ARTIGOS 


\title{
DE ALMA LAVADA E CORAÇÃO PULSANTE
}

\author{
Boris Fausto \\ Doutor em História, professor aposentado do Departamento de Ciência \\ Política da Faculdade de Filosofia, Letras e Ciências Humanas da \\ Universidade de São Paulo e membro do Grupo de Análise da \\ Conjuntura Internacional da Universidade de São Paulo.
}

\section{Resumo}

Este artigo apresenta algumas reflexões sobre aspectos que envolvem o universo do futebol, mas na perspectiva do torcedor convicto e não dos torcedores de circunstância. Ele procura entender certos meandros dessa paixão, as subjetividades que despontam e as diferentes formas e práticas de torcer criadas por esse tipo de torcedor. Como entrelaça elementos da memória individual e também da coletiva, ele revela, sobretudo, a percepção e as convicções de um destes torcedores.

\section{Palavras-chave}

futebol $\bullet$ torcedor $\bullet$ torcidas $\bullet$ memória $\bullet$ história.

Correspondência

Faculdade de Filosofia, Letras e Ciências Humanas - FFLCH/USP

Departamento de Ciência Política

Rua Prof. Luciano Gualberto, 315

05508-900 - Cidade Universitária - São Paulo - SP

E-mail: b.fausto@usp.br 


\title{
OVERJOYED AND \\ FAST-BEATING HEART
}

\begin{abstract}
Boris Fausto
Doctor in History, retired Professor of the Departamento de Ciência Política of the Faculdade de Filosofia, Letras e Ciências Humanas of the Universidade de São Paulo and member of the Grupo de Análise da Conjuntura Internacional of the Universidade de São Paulo.
\end{abstract}

\begin{abstract}
This article presents some reflections on issues involving the world of football, but in the view of the staunch supporters and not those of casual supporters. It seeks to understand certain intricacies of this passion, the subjectivities that emerge and the different forms and practices of support created by this type of fan. By interweaving elements of individual and collective memory, it reveals, above all, the perception and beliefs of one of these supporters.
\end{abstract}

\section{Keywords}

football $\bullet$ supporter $\bullet$ supporters groups $\bullet$ memory $\bullet$ history.

Contact

Faculdade de Filosofia, Letras e Ciências Humanas - FFLCH/USP

Departamento de Ciência Política

Rua Prof. Luciano Gualberto, 315

CEP 05508-900 - Cidade Universitária - São Paulo - SP

E-mail: b.fausto@usp.br 
O título pode parecer inspirado em novela barata, mas não é. Ele vem do mundo do futebol. Quem faz parte desse mundo? Com o risco de esquecer alguma categoria, faço uma lista: empresas detentoras de direitos de transmissão; dirigentes, popularmente designados de cartolas, embora ao que se saiba nunca as tenham usado; empresários de jogadores, novos personagens que brotaram do solo e floresceram depois da lei Pelé; técnicos com prazo de validade muito curto, descartados após uma breve sequência de resultados negativos; locutores de TV e de rádio, cuja maior virtude é berrar a marcação de um gol, ameaçando matar de ataque cardíaco as senhoras avessas ao futebol; juízes e bandeirinhas que deixam as respectivas mães em casa, como um recurso para aparentar calma diante dos xingamentos e das vaias; jogadores, que reproduzem com lentes aumentadas a hierarquia da nossa sociedade, recebendo na base um salário mínimo (quando recebem) e, no topo, rendimentos muito superiores aos de executivos das grandes empresas multinacionais.

Essa gente, tão diversa, tem pelo menos um ponto em comum: em escala maior ou menor, todos são profissionais do mundo do futebol, mesmo quando aparentemente não sejam, como é o caso dos "cartolas". Não vai nisso uma condenação, pois, se o dinheiro transita pela imensa maioria das atividades sociais, por que não seria assim no âmbito de um grande espetáculo de massas?

$\mathrm{Na}$ lista de personagens, falta evidentemente aquele de "alma lavada e coração pulsante" - o torcedor. Aqui, é preciso distinguir. Excluo dessa categoria os integrantes de gangues que usam o futebol como pretexto para confrontações violentas, das quais resultam mortos e feridos. Falo do torcedor com " $\mathrm{T}$ " maiúsculo, aquele homem ou mulher, menino ou menina, que vai aos estádios - ou, cada vez mais, para proteger-se, infelizmente, assiste aos jogos pela televisão -, com um único objetivo: torcer pela vitória do seu time. Alguém diria que não é bem assim porque torcedor faz apostas e joga, às vezes, na loteria esportiva. Convém perguntar por que esta não goza do mesmo sucesso da Sena. Certamente, a Sena seduz uma população bem maior, por não envolver cálculos, a não ser a numerologia criada pelo apostador. Mas, sugiro que uma parte do desprestígio da loteria esportiva vem do fato de que o torcedor, se quiser realmente tentar o êxito, teria de marcar palpites contra seu próprio time - uma traição de mau agouro.

Num mundo em que o nexo monetário está presente em quase todas as relações sociais, a paixão desinteressada do torcedor provoca perplexidade. É certo que, nos dias de hoje, muitas pessoas se dedicam ao trabalho voluntário; mas essa nobre atividade não guarda relação com o torcedor, pois tem um objetivo definido, de conteúdo humanitário. A paixão do torcedor aproxima-se da paixão dos amorosos, com a diferença de que ela tende a durar muito mais. 
Faço algumas perguntas cuja resposta não é simples. Por que o futebol se popularizou de tal forma entre nós e mais recentemente em todo o mundo, a ponto de atrair multidões, guardadas as devidas proporções, em Kabul ou em Londres, e de transformar os Estados Unidos num país estranho pela baixa popularidade do esporte bretão? Depois, que motivos nos levam a torcer para este e não para aquele time; por acréscimo, o que nos leva a enxergar em determinadas equipes o inimigo principal?

Há quem diga que uma das principais razões da extraordinária popularidade do futebol se deve à simplicidade de suas regras, suscetíveis de serem apreendidas pelo comum das gentes. Em primeiro lugar, é preciso valorizar o fato de que as regras são universais e sua alteração nada frequente. A universalidade é, aliás, uma lição para as nações que hesitam tanto em aprovar ordenamentos jurídicos supranacionais; também a permanência no tempo ensina alguma coisa à elite política brasileira, sempre seduzida por novas Constituições ou reformas constitucionais.

Porém, tenho minhas dúvidas quanto à simplicidade das regras como fator de atração porque, depois de assistir a jogos durante quase setenta anos, ainda desconheço várias delas. Mesmo se admitirmos que "a regra é clara", ela não dispensa interpretações. Muitos lances se abrem a um mundo de controvérsias, não obstante o avanço da tecnologia, ao introduzir-se a televisão e os recursos do "tira-teima". Dois exemplos são elucidativos: o dos pênaltis e dos impedimentos. É óbvio que há pênaltis claros, incontroversos, que só os mais fanáticos, ou os técnicos à beira do gramado, cumprindo seu papel teatral, atrevem-se a negar. Mas e os lances duvidosos? A intencionalidade ou a não intencionalidade, os braços ao longo do corpo ou um pouco erguidos?

Quanto aos impedimentos, as controvérsias são tantas que já se cogitou da alteração das regras para tornar as dúvidas menos constantes. Nesse caso, também há lances incontroversos, quando um atacante se coloca na "banheira", bem à frente da defesa adversária. Mas há outros sem essa clareza. É possível discutir infinitamente se houve ou não impedimento, mesmo quando a neutra tecnologia constata que o jogador " $X$ " estava impedido pela projeção da barriga, ou uns centímetros de chuteira à frente da defesa adversária; se o jogador "Y" estava impedido, mas não interferiu na jogada; ou se ele, de qualquer forma, tirou a atenção da defesa e, assim, teria participado indiretamente do lance.

Não vejo mal em tudo isso. As controvérsias interpretativas, sem paralelo em esportes como o basquete e principalmente o vôlei, dão um colorido especial às discussões das segundas-feiras, ou do meio de semana, às acusações de culpa 
ou dolo de juízes e bandeirinhas, quando o torcedor se convence de que seu time foi prejudicado.

Além disso, o universalismo das regras não impede a interpretação regional. Quantas vezes, a propósito de uma falta marcada, ouvimos dizer - "se fosse juiz europeu não marcava falta nesse tranco de jeito nenhum?”. E quantas vezes, pelo contrário, nos assombramos com a não marcação de faltas claras aos nossos olhos tropicais, que os europeus deixam passar em brancas nuvens?

Afinal de contas, creio que a paixão futebolística do brasileiro e de outros povos é um exemplo de sensibilidade estética. Nenhum outro esporte supera um futebol bem jogado, naquele tapete verde que, infelizmente, é joia rara em nossos campos. Nenhum exige, ao mesmo tempo, a existência de talentos individuais e de organização coletiva, impressa esta na designação dos pais fundadores: football association. Claro que estou falando do ponto de vista de milhões de brasileiros, pois, se me referisse à maioria dos norte-americanos, teria de admitir que, para eles, o soccer é um jogo chato a ponto de terminar, às vezes, em 0 x 0 , depois de noventa minutos.

Apesar do domínio do futebol como espetáculo de massa em nosso país, é evidente que nem todos gostam dele. Pelo menos na minha complexa classificação, o torcedor representa uma minoria. A classificação fica mais ou menos assim: há o torcedor convicto, que acompanha seu time e a seleção brasileira em qualquer circunstância, mesmo alternando períodos de depressão e de euforia; há aqueles que simpatizam com um time, mas o acompanham de longe, sem maior interesse; há os que torcem - ou as que torcem - pela "pátria em chuteiras", por ocasião das Copas do Mundo, e nada mais; há os minoritários que detestam o futebol e, por último, se não estou esquecendo alguma categoria, há os que apreciam o jogo, mas não torcem por nenhum time.

Nesse assunto, sou rigorista, como se pode deduzir do parágrafo acima. Chamei de torcedor apenas o convicto; os demais são torcedores de circunstância ou simpatizantes, a quem, neste último caso, falta um ingrediente básico: a paixão. Geralmente, uma paixão por um dos grandes clubes ou, vez por outra, idêntico sentimento por um pequeno clube. Um exemplo dos mais expressivos da última alternativa se encontra em um documentário sobre o América F. C., os diabos-rubros, que vi por acaso na televisão. Aí se percebe um pouco das razões pelo amor a esse time que mal e mal respira. Um dos entrevistados, envergando a camisa "americana", explicou: - Se eu fosse Flamengo, era um a mais e nem seria notado; o "ameriquinha" não, o "ameriquinha" precisa de mim e eu vou com ele até morrer. 
Há duas categorias mencionadas acima que chamam muito a atenção. Para quem gosta de futebol, não gostar é uma anomalia, um fenômeno inexplicável. Invadindo a esfera privada, dou o exemplo de dois de meus netos, filhos de um pai torcedor, os quais, não obstante, desprezam o esporte bretão... Pior do que esse caso é o de um ilustre sociólogo, meu amigo de muitos anos, que detesta particularmente a Copa porque os foguetes e os latidos alucinados dos cachorros não o deixam ler nem dormir sossegado. Aliás, na época da ditadura, sugeri a ele não contar a mais ninguém seus sentimentos porque poderia ser enquadrado na lei de segurança nacional, por crime de lesa-pátria.

Personagem curioso, embora muito raro, é o que gosta de futebol, pelo jogo em si, mas não torce por time algum. Encontrei uma dessas figuras na geral do Pacaembu, aí pelo início da década de 1950. Era um jogo São Paulo x Corinthians e uma falta marcada contra o alvinegro na linha da grande área provocou uma enorme discussão: foi mesmo falta ou foi pênalti como berravam os são-paulinos? Antes da falta ser cobrada - e como se demora, no Brasil, a cobrança das faltas perigosas - um dos supostos são-paulinos, que garantiam ter sido pênalti, foi duramente contestado por um corintiano: - Deixa de ser fanático, onde você viu esse pênalti? - Não sou fanático, não torço prá ninguém. O corintiano, antes da cobrança, respondeu indignado: - Essa é boa! Quem vem no campo é prá torcê.

Falando de nós, os torcedores convictos, como explicar o gosto pelo futebol e a escolha de um time de absoluta preferência? Absoluta sim, porque quando se é corintiano, flamenguista, atleticano etc. de verdade, não há espaço para dividir a paixão em frases do gênero: "no Rio, sou Botafogo"; ou, "em São Paulo, sou Santos" e por aí vai. A explicação mais comum de uma escolha liga-se à tradição familiar. Nas maternidades, há pais que colocam na porta do quarto do filho ou filha recém nascido, uma camiseta minúscula com as cores de seu time. Cheguei a ver mesmo, em certa ocasião, uma carteirinha de sócio, não me lembro de que clube, em nome do ilustre rebento. Nessa linha, há também o reverso da medalha - o dos filhos que torcem para um time rival daquele de preferência do pai, para demonstrar muito cedo sua independência.

Há ainda opções não derivadas da tradição familiar, seja para lhe dar sequência, seja para contrariá-la. No meu caso, fiz uma opção pelo Corinthians aos onze anos e confesso ter fracassado na missão de dar continuidade à minha paixão. Nem sei se devia dizer isso, mas tenho dois filhos palmeirenses. Quando contei essa história ao "seu" Jorge, um motorista de praça corintiano roxo, expliquei que tinha admitido a troca do Corinthians pelo Palmeiras porque meus meninos, bem pequenos, não aguentavam a péssima fase corintiana, em contraste com o Palmeiras da academia. Tinha aceitado também a mudança - conclui -, movido 
pelo espírito democrático. "Seu” Jorge, chileno, há décadas no Brasil, me deu uma lição: - Democracia em política, tudo bem. No futebol, francamente, é demais.

Em todo caso, tenho alguns atenuantes para meu erro. Em primeiro lugar, vetei a troca do Corinthians pelo São Paulo, inimigo principal, por razões pessoais que fogem ao alcance deste texto. Como resultado, com filhos palmeirenses e um neto que seguiu o pai, não tenho para com o alviverde a tradicional repulsa manifestada pelos torcedores do "timão". De quebra, meu neto "boleiro" é palmeirense fanático. Nasceu e vive no Rio de Janeiro, fala "carioquês", acha São Paulo muito feia, menos o Parque Antártica, onde comparece na medida do possível, para admiração dos torcedores a seu redor. Penso que ele é o único carioca torcedor do Palmeiras e, por isso, bem merecia uma homenagem do clube.

O episódio da troca, na meninice de meus filhos, representou uma exceção paternal à regra de ouro segundo a qual o torcedor digno desse nome não muda de time, por mais que se decepcione com os insucessos. Esse comportamento deveria ser absorvido pelos políticos brasileiros, dispostos a trocar de camisa, ou melhor de partido, a todo o momento, em geral por razões mesquinhas.

O mais significativo da paixão talvez não seja o momento da escolha, mas a natureza da identificação, ao longo dos anos, com determinado time. No passado, ela era fácil de ser entendida: os símbolos do clube - as cores, a bandeira, o uniforme, os jogadores mais representativos - constituíam-se em nítidos elementos da identificação. Hoje, poucos desses símbolos permanecem. O uniforme límpido transformou-se numa colcha de retalhos profana, em que os anúncios se multiplicam e são disputados pedaço por pedaço, no caso de jogadores famosos; em São Paulo, as bandeiras não entram nos estádios para se evitar violências; os jogadores representativos são raros e, aliás, por isso mesmo muito apreciados, como acontece com Marcos no Palmeiras, ou Rogério Ceni no São Paulo.

Nos tempos de outrora, eram muitos os jogadores que simbolizavam uma equipe. Entre outros nomes, o Flamengo foi o meia Zizinho, que infernizava os paulistas no acirrado campeonato brasileiro entre Estados; o Corinthians foi José Augusto Brandão, o gigante cor de ébano, imorredouro centro médio; o Palestra, o goleiro Oberdan Cattani, que anda a merecer uma estátua no Parque Antártica; o São Paulo, José Carlos Bauer, brilhante médio direito, tão clássico quanto disciplinado; o Santos foi Pelé, ícone da Vila e do Brasil inteiro. Hoje, os profissionais andam de lá para cá, a ponto de só os torcedores mais fanáticos saberem a escalação de seu time. Além disso, a discutida globalização sangrou o futebol do Brasil e de outros países latino-americanos com uma fúria devastadora, mas explicável, pois encheu (e como!) os bolsos de alguns astros e de seus empresários. Mas, para o torcedor, o fenômeno da globalização é um martírio insuportável, 
especialmente quando se abre a janela de transferências do futebol europeu. De uma hora para outra, times se desmontam e jogadores que pareciam identificar-se com seus clubes partem para o El-Dorado, deixando vazios lembrados por muito tempo, como se fossem mortos queridos desaparecidos para sempre.

Apesar de tudo, o torcedor continua torcedor, resiste à camisa manchada pela propaganda, à rotação de jogadores, às incursões imperialistas que levam os melhores jogadores e os devolvem gastos, na melhor das hipóteses, em fim de carreira. Para o torcedor, seu time continua a representar o "bem", virtude amplíssima, sem contornos definidos, inabalável diante das vicissitudes da vida.

Por outro lado, vale a pena distinguir o torcedor individual da torcida - um ser coletivo, nascido dos indivíduos, mas inexplicável se tomado como simples soma destes. Há quem diga que a massa é imprevisível, injusta, grosseira, irracional. É difícil negar que não haja uma parcela de verdade em cada um desses qualificativos. Porém, eles não dão conta da complexidade desse ser coletivo, parte integrante e necessária de qualquer jogo de futebol. Basta lembrar o que acontece quando alguma federação resolve obrigar a realização de um jogo com portões fechados. Pela televisão, a cena é fantasmagórica: arquibancadas vazias, silêncio absoluto, jogadores displicentes, pois é impossível prescindir da multidão que incentiva e ao mesmo tempo incomoda. De fato, o som da torcida dá o termômetro do jogo. Explosão quando o time entra em campo, euforia quando consegue uma grande vantagem, tensão diante do resultado incerto, rumores diante de uma exibição decepcionante, ruidosas vaias, explosões de alegria, tudo isso se expressando no rosto e em muitas outras partes do corpo. Não por acaso, o Dicionário Houaiss assim enuncia um dos significados do verbo torcer: "contrair ou contorcer o corpo, em razão de dor física, desespero, riso".

O palco são obviamente os estádios, mas torcemos também ouvindo, ou assistindo aos jogos pela televisão. $\mathrm{O}$ rádio foi o primeiro intermediário entre o torcedor e o que estava acontecendo em campo. Até hoje ele é valioso para porteiros de prédio e motoristas de táxi, quando não incomodados por clientes ignorantes. As ondas hertzianas, como se dizia outrora, deram origem a locutores famosos, cada qual com seu estilo, seus bordões próprios, a exemplo do filosófico "o tempo passa", ou do brega-romântico "abrem-se as cortinas do espetáculo". Locutores e ouvintes estabelecem uma cumplicidade baseada na imaginação, uma imaginação angustiante como um voo às cegas: o locutor dá às irradiações um ritmo próprio, de tal forma que é difícil perceber com certeza a qualidade do jogo, os acertos e erros do juiz, se a bola está no grande círculo, ou na pequena área.

No passado, em vez de controvérsias nascidas de lances vistos de muito perto e infinitamente repetidos pela televisão, a fonte confiável eram certos locutores 
prestigiosos, um jornal especializado como a $A$ Gazeta Esportiva, dirigida por Carlos Joel Nelli, as crônicas de Thomaz Mazzoni, o Olimpicus, do Joreca (Jorge de Lima), ou do Ary Silva, que dizia matutar seus escritos quando vinha no bonde Santana para o centro da cidade. As discussões entre os torcedores corriam mais ou menos assim - Foi gol roubado, você não ouviu a transmissão do Pedro Luis? A transmissão podia ser enfatizada ou substituída pelos argumentos dos cronistas merecedores de fé. Quanto à arbitragem, uma palavra decisiva para dirimir dúvidas era a de Leopoldo Santana, "o juiz do árbitro", que analisava a conduta de "sua senhoria", após cada irradiação.

Pensando no futebol de São Paulo, que conheço mais de perto, é interessante assinalar os traços étnicos das torcidas, embora eles tenham perdido força, em meio à grande transformação demográfica da cidade e do Estado. Claramente, $\mathrm{o}$ Palmeiras - o Palestra Itália - tem um núcleo básico de torcedores descendentes de italianos a que se incorporou gente de outras etnias, em menor proporção. Como se sabe, o entorno do Palmeiras é um bairro predominantemente italiano - a Vila Pompeia - ainda que a designação nada tenha a ver com a cidade do Império Romano, destruída pela erupção do Vesúvio. O loteamento original foi aberto por Rodolfo Miranda, um empresário e prócer do Partido Republicano Paulista, pelo qual chegou a ser senador. A "Pompeia” do loteamento não faz alusão ao Lácio, pois foi uma homenagem à mulher do senador, Aretusa Pompeia. Em todo caso, convém lembrar que algumas ruas do bairro foram denominadas com nomes de imperadores romanos: Tito, Vespasiano, Deocleciano.

Lusos são lusos, não há novidade nisso, mas o multirracialismo corintiano merece uma especial referência. É coisa sabida, mas não custa relembrar. Fundado por imigrantes do Bom Retiro, espanhóis em sua maioria, e também por alguns italianos (1910), o alvinegro do Parque São Jorge incorporou negros e mulatos e um punhado de branquinhos, além de ter-se tornado o time dos nordestinos de qualquer coloração que começaram a chegar a São Paulo, a partir de meados da década de 1930. Os espanhóis e seus filhos permaneceram integrantes da "fiel", mas quase todos os italianos se foram, após uma divergência da qual se originou a fundação do Palestra, em 1914. Os poucos que ficaram - os Tussato, os Sapupo - valem por todos os que se foram, entre outras razões, por aguentarem odiosas provocações: - Como você pode ser corintiano com um sobrenome desses? Bem pensando, não censuro a pergunta pois, afinal de contas, o futebol não é o reino da compreensão e eu, por exemplo, não consigo entender como um negro ou um mulato pode ser são-paulino.

Se os domínios do Palestra (como seria bom retomar o nome, perdido na Segunda Guerra Mundial!) são uma parte da zona oeste de São Paulo, o reino 
corintiano implantou-se na zona leste, com destaque para o bairro do Tatuapé. No Tatuapé (caminho do tatu), a partir das últimas décadas do século XIX, famílias italianas como os Marengo, os Camardo, formaram chácaras destinadas à cultura da uva e à produção de vinho. Desviando por um trilho da memória, lembro as carroças e as precárias caminhonetes que, na minha infância, percorriam as ruas da cidade, com um pregão autêntico, não aquele gravado, das terríveis pamonhas de Piracicaba: - Uva, uva, uva, uva preta do Marengo! O falecido Vicente Matheus gostava de contar uma história a respeito de sua ligação com o bairro. A família insistira, em certa época, que ele fosse morar no Morumbi, uma sugestão recusada terminantemente: - No Morumbi (logo no Morumbi, digo eu...), vou ser um desconhecido; aqui não. Aqui, quando eu ando na rua, todo mundo me cumprimenta e tira o chapéu, mesmo sem usar chapéu: "Matheus, Matheus", eles falam e pode ser corintiano, palestrino, são-paulino; todos me respeitam.

Matheus, sem ter diploma, era mais sábio que um médico meu conhecido. Corintiano impecável, ele me disse, em meio a um diagnóstico, que mora no Jardim Europa e ali, durante os jogos, há um desinteressado silêncio, ou comemorações, se o São Paulo ganha ou o Corinthians perde. Quando eu disse que ele devia ir morar no Tatuapé, emendou: - É, eu devia voltar prá lá.

No capítulo da gozação entre torcidas rivais, faço um elogio insuspeito à torcida palmeirense. Assumir na íntegra o "porco" e transformá-lo de injúria em motivo de orgulho revela uma rara capacidade de transformação do significado dos símbolos, como talvez digam os antropólogos. Não me lembro de outra torcida que tenha conseguido essa façanha. Também, não há como atribuir a si mesmo a condição de peixeiro, de maloqueiro, ou de bambi. Paro por aqui antes de ser linchado pelo crime de ser politicamente incorreto, ainda que, no meu entender, essa categoria não exista no mundo tosco, brilhante, brutal, sublime, do torcedor de futebol.

Recebido: 26/10/2009 - Aprovado: 24/05/2010 